1 Gilmour JR. Giant cell chronic arteritis. f Pathol 1941;53:263.

Arnung K, Nielsen IL. Temporal arteritis and gangrene of the tongue. Acta Med Scand $1979 ; 206: 239-40$

3 Reboul M, Boissonnas A, Cachin M. Necrose du cuir chevelu et de la langue relevant une malaide de Horton. Nouv Presse Med 1975;4:1971-8. Dufetelle JP, Tapie B. Necrose linguale au cours d'une maladie de Horton
Rev Stomatol Chir Maxillofac 1976;77:1013-9.

(Accepted 20 December 1984)

Department of Medicine and Department of Plastic Surgery Diakonissestiftelsen, Peter Bangsvej 1, 2000 Copenhagen F, Denmark

$S$ J SIEMSSEN, MD, resident

O D LARSEN, MD, senior registrar

A MCNAIR, MD, senior registrar

Correspondence to: Dr A McNair, Fresiavej 2, 3450 Allerød, Denmark.

\section{Erythema nodosum and circulating immune complexes in acne fulminans after treatment with isotretinoin}

The syndrome of acne fulminans includes severe ulcerating cystic acne, fever, and arthralgia. ${ }^{1}$ Other documented features include microscopic haematuria, an increased erythrocyte sedimentation rate and white cell count, ${ }^{1}$ anaemia, ${ }^{2}$ myalgia, ${ }^{1}$ and, in one case, erythema nodosum. ${ }^{3}$ Circulating immune complexes have not previously been reported, although their presence is suggested by the findings of arthralgia, microscopic haematuria, and erythema nodosum.

In the past three years we have seen three patients with erythema nodosum and acne fulminans, which in two cases appeared to have been triggered by treatment with the recently introduced analogue of vitamin $\mathrm{A}$, isotretinoin. Evidence of circulating immune complexes was sought in these two patients, and we report our findings.

\section{Case reports}

Case 1-An 18 year old man had had acne for several years which had recently become resistant to conventional treatment. He was treated with isotretinoin $0.5 \mathrm{mg} / \mathrm{kg}$ daily, increasing after four weeks to $1 \mathrm{mg} / \mathrm{kg}$ daily Three weeks later he was admitted to hospital with fever, crusted and ulcerating lesions on his chest, and erythema nodosum on his shins. In vestigations showed the following abnormalities: erythrocyte sedimentation rate $70 \mathrm{~mm}$ in the first hour; haemoglobin concentration $11.9 \mathrm{~g} / \mathrm{dl}$; white cell count $11.5 \times 10^{9} / 1$, neutrophils $80 \%$; platelet aggregation test for circulating IgG immune complexes yielded a positive result on two occasion at $1 / 160$ dilution (normal less than 1/20); and faecal occult blood was weakly positive on three consecutive occasions. Results of latex and sheep cell agglutination tests, antinuclear factor titre, and results of urine microscopy were normal or negative. Propionibacterium acnes was isolated from acne lesions.

Case 2-A 21 year old Asian man with severe nodulocystic facial acne unresponsive to oral antibiotics was treated with isotretinoin $1 \mathrm{mg} / \mathrm{kg}$ daily. His acne became progressively more inflamed over the ensuing three weeks, with the development of arthralgia, lesions similar to those of pyogenic granuloma on the chest, ${ }^{4}$ and erythema nodosum on his shins. The following abnormalities were found: erythrocyte sedimentation rate $50 \mathrm{~mm}$ in the first hour; white cell count $14.3 \times 10^{9} / 1$, neutrophils $67 \%$; platele aggregation test for circulating IgG immune complexes yielded a positive result on two occasions at $1 / 160$ dilution (normal less than $1 / 20$ ); and serum IgG concentration was $21 \cdot 7 \mathrm{~g} / 1$ (normal $8 \cdot 0-18 \cdot 0 \mathrm{~g} / \mathrm{l}$ ). Microscopy of urine yielded normal results.

In both cases symptoms responded rapidly to moderate doses of prednisolone $(25-30 \mathrm{mg}$ daily). Improvement was accompanied by a fall in the titre of circulating immune complexes to normal values within four weeks. Isotretinoin was continued at $1 \mathrm{mg} / \mathrm{kg}$ daily and achieved excellent results in three to four months.

\section{Comment}

Acne fulminans is a rare complication of severe acne. The two patients reported on here developed the condition after starting treatment with isotretinoin. Although acne does commonly worsen in the first few weeks of treatment with isotretinoin, ${ }^{5}$ we are not aware that it has previously been implicated as a precipitant of acne fulminans.

Circulating immune complexes are found when erythema nodosum occurs in other conditions such as sarcoidosis, and their presence has been predicted in acne fulminans. ${ }^{2}$ On the basis of the clinical findings in a patient with acne fulminans and erythema nodosum Williamson et al postulated that an Arthus reaction was taking place. ${ }^{3}$ They were able to show an exaggerated response to an intradermal injection of $P$ acnes suspended in saline, and suggested that this antigen might also play a part in the Arthus reaction. They did not, however, show the presence of circulating immune complexes. Using the platelet aggregation test, a reliable method for detecting soluble IgG complexes, we confirmed that circulating immune complexes may be found in acne fulminans.

1 Lane AM, Leyden JJ, Spiegel RJ. Acne arthralgia. F Bone foint Surg [Am] 1976; $58: 673-5$

2 Darley CR, Currey HLF, Baker $H$. Acne fulminans with arthritis in identical

3 Williamson DM, Cunliffe WJ, Gatecliff M, Scott DG. Acute ulcerative acne conglobata (acne fulminans) with erythema nodosum. Clin Exp Dermatol $1977 ; 2: 351-4$

4 Exner JH, Dahod S, Pochi PE. Pyogenic granuloma-like acne lesions during isotretinoin therapy. Arch Dermatol 1983;119:808-11. Katz RA, Jorgensen H, Nigra TP. Flare of cystic acne from oral isotretinoin.
f Am Acad Dermatol 1983;8:132-3.

(Accepted 28 December 1984)

Manchester Skin Hospital, Manchester M3 3HL

J K KELLETT, MRCP, senior registrar

M H BECK, MRCP, consultant

R J G CHALMERS, MRCP, consultant

Correspondence to: Dr J K Kellett.

\section{Is a local anaesthetic necessary when using fine gauge spinal needles?}

Over the past 100 years since Bier introduced spinal anaesthesia in man needles for this procedure have improved in design, becoming finer and sharper. The use of fine gauge needles lessens the risk of headache after lumbar puncture. ${ }^{1}$ The most commonly used sizes are 22 gauge, 23 gauge, and 25 gauge. The use of 25 gauge needles reduces the incidence of headache after lumbar puncture to less than $2 \%{ }^{2}$ The 25 gauge needle is flexible, however, and the use of an introducer is recommended.

Drummond and Scott have shown that needles may be more accurately directed in the midline if the bevels of the needles face caudally rather than laterally. ${ }^{3}$ This method has been followed by one of us (GRP), who finds it unnecessary to use an introducer in routine clinical practice with 25 gauge spinal needles.

To make insertion of a spinal needle as painless as possible it is almost universal practice to infiltrate the skin with a small volume of local anaesthetic using a 25 gauge intravenous needle. This is painful owing to the stinging sensation of the local anaesthetic. It seems unnecessary to use infiltration anaesthesia if a lumbar puncture is performed with a 25 gauge needle alone. As discrimination of needle size in the lumbar region is said to be poor, it may be unnecessary to use infiltration anaesthesia for sizes other than 25 gauge.

We have tried to compare the pain caused by the insertion through the skin of spinal needles in common use to see if they can be discriminated and to see if infiltration anaesthesia is necessary with the use of fine needles.

\section{Subjects, methods, and results}

Twelve anaesthetists from this department, of all grades and both sexes, volunteered for the study. The $10 \mathrm{~cm}$ visual analogue scale ${ }^{4}$ was explained to them. The conventional limits of the scale are no pain at all and the worst pain you could possibly imagine. The scale was modified so that the upper limit of pain was the pain caused by the insertion of an 18 gauge spinal needle (Becton Dickinson, España, SA) through the skin without local infiltration anaesthesia. This avoided crowding at the lower end of the scale.

An area $15 \times 15 \mathrm{~cm}$ around the spinous processes of L3 and L4 was cleaned using a chlorhexidine spray (Dispray, Stuart Pharmaceutical) and dried with a gauze swab. A previous study of 10 volunteers had shown sensitivity over the spinous processes to be no different from that of skin more laterally. An 18 gauge spinal needle was introduced through the skin to give the upper limit of the visual analogue scale. The same investigator then inserted 